\title{
Acerca de la feminización de profesiones. Caso: la docencia en preescolar en la Ciudad de México
} \section{Martha Karina Vargas Pérez ${ }^{3}$ y Claudia Ivonne Hernández Ramírez ${ }^{4}$}

Jorge García Villanuevaํㅜ, Diocelina Ávila Rodríguez²,

\section{Resumen}

La presente investigación aborda la feminización en Educación Preescolar en la Ciudad de México. Se realizaron entrevistas a profundidad a cuatro maestros de este nivel educativo. Los hallazgos indican que los roles de género se encuentran arraigados en la voz y expectativas de la población mexicana, difundidas a través de las instituciones sociales, como el Estado, la escuela y la familia. Además, se encontró que las autoridades educativas, las madres y padres de familia, refuerzan el estereotipo de la masculinidad dominante, que lo caracteriza con aquellos atributos que enaltecen la razón, la fuerza, la agresividad y la heterosexualidad, dudando de la capacidad de los hombres para desempeñarse como docentes en preescolar, atribuyéndoles la etiqueta de gay o abusadores sexuales en potencia. Los argumentos muestran que, por razones de sexo, las mujeres son naturalmente aptas para 
la docencia debido a que poseen cualidades femeninas relativas a la ternura, la fragilidad, la dulzura y la maternidad.

Palabras clave: roles de género, estereotipos de género, feminización, prejuicio, educación preescolar.

\section{Abstract}

This research addresses the feminization in Preschool Education in Mexico City. Four teachers of this level were interviewed. The findings indicate that gender roles are rooted in voice and expectations of the Mexican population, disseminated through social institutions such as the State, school and family. In addition, it was found that education authorities, mothers and fathers, reinforced the stereotype of the dominant masculinity that characterizes those attributes that highlight the reason, strength, aggressiveness and heterosexuality, doubting the ability of men to serve as teachers in preschool, giving them the label of gay or potential abusers. The arguments show that, for reasons of sex, women are naturally fit to become teachers because they have female qualities relating to tenderness, fragility and motherhood.

Keywords: gender roles, gender stereotype, feminization, prejudice, preschool education. 


\section{Introducción}

Desde la visión de Burin y Meler (1998) el género se define como el conjunto de conductas atribuidas a los hombres y a las mujeres. Y se articula en tres momentos básicos, a saber, la asignación de género, la identidad de género y el papel o rol de género, este último conformado por el conjunto de normas y prescripciones que dicta la cultura acerca de los comportamientos femenino y masculino (Rocha y Díaz, 2005; García, Meza y Rodríguez, 2004). La adopción de estas normas tiene lugar desde la socialización de las niñas y los niños, debido a que la sociedad considera comportamientos diferenciales y adecuados según el sexo de las personas, en el caso de las mujeres se espera que éstas manifiesten sensibilidad y afectividad; de los varones que denoten independencia y agresividad (Lara, 1993).

Por su parte, Olvera (1997) menciona que el proceso de adopción de los roles de género tiene dos facetas en las que está el descubrimiento de éstos y la discriminación en la adopción de los mismos, según se trate de un varón o de una mujer. Los roles de género son todos aquellos papeles sociales asignados según el sexo, así como las normas y expectativas asociadas a las posiciones que mujeres y hombres ocupan de forma desigual en organizaciones o instituciones sociales (Benería y Roldan, 1987; Lara, 1993; Szasz, 1998), esto también incluye las diferencias sociales o creencias que una sociedad adscribe a varones y mujeres, las cuales pueden diferir según el contexto, y que, a su vez, funcionan como mecanismos cognoscitivos y perceptivos por los cuales según García, Meza y 
Rodríguez (2004) la diferenciación biológica se convierte en una diferenciación social, que delimita la feminidad y la masculinidad.

Al respecto, Barberá, Ramos y Candela (2006) argumentan que socialmente, se predetermina desde la elección de carrera, la atribución de género de las profesiones y se considera que hay trabajos más aptos para las mujeres y otras labores más adecuadas para los hombres, diferencias vinculadas con los estereotipos de género tradicionales donde las profesiones masculinas son las que requieren fuerza física y las femeninas tienen que ver con la imagen, la limpieza y el cuidado (Dubet, 2005; Valle y Smith, 1995; Cortada de Kohan, 2005).

\section{Los roles de género y prejuicio hacia los maestros de Educación Preescolar}

El rol o papel social es el tipo de conducta esperada por las personas que ocupan un lugar dentro de la sociedad, debido a que se ha enlazado el funcionamiento de la sociedad a las características y al comportamiento de los seres humanos. La repetición y el estereotipo de la conducta se perpetúan en el imaginario colectivo y la memoria individual de manera obstinada (Fernández, 1995).

Ser hombre o ser mujer es resultado de un proceso psicológico, social y cultural a partir del cual se asigna un significado a lo masculino y a lo femenino. Los significados están conformados por reglas, obligaciones, características, comportamientos, prohibiciones, expectativas y valores que son transmitidos y reforzados en las 
personas como parte de un proceso de identidad para aprender a ser hombres y mujeres (Rocha y Díaz, 2011).

Los roles de género constituyen buena parte de los prejuicios en torno a hombres y mujeres, de acuerdo con Tajfel (1981) el prejuicio es un tipo de evaluación, una actitud asumida, ya sea negativa o positiva, a favor o en contra que posee un grupo y se detona en la aceptación o el rechazo hacia los "otros". Desde la infancia, los seres humanos aprenden a discriminar lo que es propio del género, esas percepciones pasan por ese tamiz para asumir una postura al respecto, de esa manera van siendo asimilados y alimentados diferentes prejuicios de género.

Los estereotipos de género son, por su parte, aquellas percepciones permanentes de los papeles asignados a hombres y mujeres, los cuales se convierten en un sistema de creencias acerca de las características, atributos y comportamientos que se piensa son propias, esperables y adecuadas para éstos, se transmiten de generación en generación y van del "ser" al "deber ser", es decir, los estereotipos son esquemas cognitivos (Fernández, 1995). Así, los comportamientos asociados al género son la manifestación conjunta de los papeles y los estereotipos con otros rasgos de la personalidad, las habilidades, las percepciones y creencias sobre sí mismo como varón o mujer (Lara, 1993).

Sin embargo, las creencias y percepciones de las habilidades y actividades diferenciales de varones y mujeres pueden afectar al comportamiento, confirmando las creencias genéricas que las personas tienen sobre sí mismas pues se sabe que a lo masculino se 
le han atribuido características como: el valor, la fuerza, la agresividad y la racionalidad; mientras que a la feminidad se le confiere el sentimentalismo, la fragilidad, la ternura, la dulzura y se define como opuesta e inferior a la masculinidad (Beauvoir, 1982).

Así, las expectativas asociadas a los papeles sociales se transforman en diferencias reales según el sexo, limitando la capacidad de mujeres y hombres para trascender las posiciones asignadas. Por otro lado, las expectativas tienen una influencia directa sobre el comportamiento y las disposiciones conductuales que se basan en la conformidad de las personas que tienden a comportarse de modo consistente con esos papeles y con las consecuencias que esperan de su desempeño (Lara, 1993; Fernández, 1995).

A las mujeres, durante mucho tiempo, en diferentes regiones de México, se les asignó las labores del hogar, esto es, el cuidado al esposo, a las personas enfermas, y, principalmente, a la crianza, razón por la cual, fueron señaladas como las únicas y mejor capacitadas para esta última actividad.

Sin embargo, las mismas demandas sociales han hecho que los hombres incursionen en ámbitos distintos a los que usualmente eran sede de su desarrollo profesional, por ejemplo, los estudios contemporáneos occidentales de género señalan que la jerarquía social en la que aparecen las mujeres frente a los hombres en desventaja, el lugar "privilegiado" que rodea la imagen masculina se ve opacado en determinados ambientes sociales, especialmente, entre los pocos que dominan las mujeres, por caso el que indaga este estudio: hombres dedicados a la docencia en Educación Preescolar (García, 2010). 
En el ámbito laboral, como en muchos otros, se espera o bien se tiene la expectativa de que el hombre se emplee en sitios propios de su género, es decir, en trabajos considerados como masculinos, trabajos donde se haga uso de sus cualidades físicas, en el sentido de utilizar el cuerpo como un medio para demostrar hombría (Huerta, 1999). Corsi (1995) plantea que el centro de la masculinidad dominante es la restricción emocional, puesto que en los hombres son signos de feminidad que deben evitarse (por la inferioridad que denota frente a la masculinidad). Esto, permite definir y tipificar las ocupaciones que son desempeñadas en su mayoría por personas de un mismo sexo y que conllevan la expectativa asociada de que "es como debe ser", de que son "actividades para hombres" o "actividades de mujeres".

En los resultados de la investigación realizada por Mendoza (2004), los hombres perciben las matemáticas (ingenierías) relacionadas directamente con el dominio masculino, representando fuerza y poder. Y se reporta que las ciencias de la educación es un área meramente femenina. Además, se observa el predominio de una cultura patriarcal de la sociedad mexicana, en donde se destaca que el papel de las mujeres se ubica en la casa, el cuidado de las hijas e hijos porque muestran un interés nato por lo social y lo humano. En correspondencia, King (1998) afirma que existe el supuesto de que la enseñanza en la primera infancia constituye un acto de cuidado promovido por la ternura, motivo por el cual se espera que las mujeres se encarguen de esa labor considerándose un trabajo exclusivo para ellas. 
Las desigualdades de género en el ámbito de Educación Preescolar se manifiestan en las tareas destinadas a los hombres, esto es, en la ocupación de puestos como representantes sindicales, asesores pedagógicos y directores de escuelas. En este contexto, existe una colaboración de la institución educativa para que los hombres reafirmen su hombría y las mujeres reafirmen su instinto maternal. Y bajo esta lógica, si un varón desea trabajar en el nivel preescolar, se presupone a menudo que es afeminado, homosexual y/o pedófilo (Blount, 2005; Fifield y Swain, 2002; Weems, 1999). Por ello la población masculina es mínima en este ámbito (Farquhar, 1997).

\section{Estrategia de Acercamiento}

La presente investigación se efectúo bajo el enfoque cualitativo descriptivo, con base en los criterios propuestos por Selltiz (1980), Colás, Buendía y Fuensanta, (1998); la finalidad es comprender e interpretar la realidad tal y como es entendida por el profesorado participante en el contexto estudiado y obtener información para caracterizar la docencia en la Ciudad de México partiendo de la experiencia de hombres dedicados a esta labor.

\section{Participantes}

A través de la técnica de bola de nieve, la muestra quedó conformada por 4 participantes que respondieron a los siguientes criterios: a) Ser licenciado en Educación Preescolar y b) 
ejercer la licenciatura en Educación Preescolar o haber estado en un periodo no mayor a 6 meses. Para guardar la confidencialidad de cada profesor, la identificación se realizó con la simbología (P) para denotar a cada participante seguido del número de orden, así sucesivamente. En la tabla 1 se muestran las características particulares de cada integrante (ver tabla 1).

Tabla 1. Características de los participantes

\begin{tabular}{cccccc}
\hline Participante & $\begin{array}{c}\text { Edad } \\
\text { (años) }\end{array}$ & $\begin{array}{c}\text { Estudios/formación } \\
\text { profesional }\end{array}$ & $\begin{array}{c}\text { Experiencia } \\
\text { (años) }\end{array}$ & $\begin{array}{c}\text { Empleo } \\
\text { actual }\end{array}$ & Puesto actual \\
\hline P1 & 21 & $\begin{array}{c}\text { Lic. psicología gene- } \\
\text { ral. UNAM- FES- Z }\end{array}$ & 4 & $\begin{array}{c}\text { Preescolar } \\
\text { privado }\end{array}$ & Profesor \\
\hline P2 & 25 & $\begin{array}{c}\text { Lic. Psicología educa- } \\
\text { tiva UPN-Ajusco }\end{array}$ & 4 & $\begin{array}{c}\text { Preescolar } \\
\text { privado }\end{array}$ & Profesor \\
\hline P3 & 43 & $\begin{array}{c}\text { Estudiante de la Lic. } \\
\text { en Psicología educa- } \\
\text { tiva. UPN- Ajusco }\end{array}$ & 13 & \multicolumn{3}{c}{$\begin{array}{c}\text { Preescolar } \\
\text { público }\end{array}$} & Profesor de \\
inglés
\end{tabular}

Fuente: Elaboración propia

\section{Técnicas e instrumentos}

Se utilizó por técnica la entrevista a profundidad con base en Taylor y Bogdan (1987), con el propósito de comprender la 
perspectiva manifestada por cada docente a fin de ilustrar sus experiencias o situaciones de un evento específico, como instrumento, se elaboró una guía de entrevista, la cual permitió explorar y dar seguimiento al discurso de cada participante (Coolican, 2005). La guía de entrevista se conformó por cinco categorías de análisis: ayudantes, obstáculos, ventajas, desventajas y prospectiva; mismas que sirvieron para efecto del estudio de la información recabada (ver tabla 2).

Tabla 2. Categorías de análisis

Categoría

\section{1.- Ayudantes}

Refiere a las personas y factores que ayudaron a colocarse y/o mantenerse como docentes de preescolar.

Identifica a las personas y factores que dificultaron el colocarse

2.- Obstáculos y/o mantenerse como docentes de preescolar, o bien que favorecieron la separación del ejercicio de dicha profesión.

Describe los beneficios personales y sociales que ven los entre3.- Ventajas vistados en el ejercicio de la docencia en preescolar por parte de hombres.

Describe los factores desmotivantes y no favorecedores tanto

4.- Desventajas personales como sociales que ven los entrevistados en el ejercicio de la docencia en preescolar por parte de hombres.

5.- Prospectiva Determinan las expectativas profesionales que tienen los entrevistados como profesores de preescolar.

Fuente: Elaboración propia. 


\section{Análisis de resultados}

Los estereotipos de género se encuentran en el extenso de las esferas sociales en México, la educación no es la excepción (Galofré, Generelo y Pichardo, 2006) porque en ésta se integran los saberes académicos, se suman los conocimientos de la familia y la sociedad, por ello no resulta sorprendente encontrar que el machismo y el sexismo siguen siendo brújula para el establecimiento del deber ser, de lo permitido y lo prohibido. Bajo esta perspectiva, a continuación se muestran los resultados de la investigación.

\section{a) Ayudantes}

Este factor responde a las personas y circunstancias que favorecieron la permanencia o inclusión de los docentes en el ámbito de Educación Preescolar. En la figura 1 se observan las categorías y subcategorías que se establecieron (ver figura 1).

a) Factor personas

Influencia familiar y la influencia de compañeros o amigos tiene una
Figura 1. Interacciones, situaciones y personas que favorecieron a la práctica docente

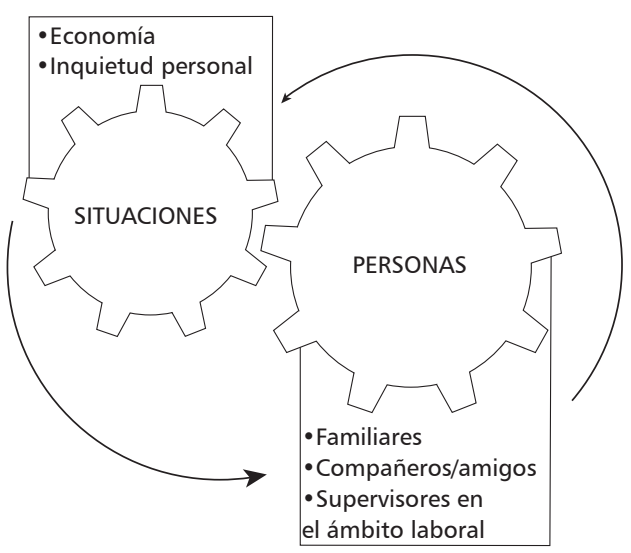


incidencia significativa, fueron esas dos esferas las que propiciaron la incursión laboral en la Educación Preescolar; sin embargo, una vez dentro del ambiente escolar, fueron los jefes y supervisores quienes les ofrecieron una plaza a los participantes P3 y P4.

b) Factores situacionales

El interés económico fue un factor decisivo para los P1, P4 y P2, dichos participantes enfatizaron que necesitaban un trabajo rápido, con remuneración constante, debido a que, su situación económica en ese momento era precaria, "los contratos eran por honorarios" afirmó P4.

En cuanto a la inquietud personal de experimentar la docencia en preescolar, el P3 hizo referencia a esta situación:

Era mi inquietud de preferir hacerlo [trabajar] en preescolar. Quería ver qué se sentía... porque yo escuchaba que decían: "los pequeñitos aprenden más" o "son como esponjitas" y todo eso. Entonces era más que nada mucha inquietud también.

\section{b. Obstáculos}

El obstáculo principal que reportaron los participantes, es atribuido al establecimiento de los roles y estereotipos de género correspondientes a una cultura machista. Roles de género 
reproducidos por la sociedad, enmarcando la participación de mesas directivas y madres y padres de familia como principales actores. A su vez, otro gran obstáculo fue la defensa de los atributos que un hombre masculino debe tener ante los otros y, por ende, los prejuicios personales en torno a éstos (ver figura 2).

\section{Figura 2}

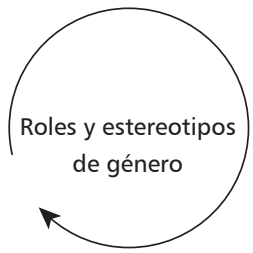

- Actores

- Mesas directivas

- Padres de familia

-Abuso sexual

-Prejuicio de género

-Prejuicios personales

\section{-2.1 Roles y estereotipos de género}

La presencia de estereotipos y roles de género en Educación Preescolar lo expresan acertadamente los participantes P4 y P2 de la siguiente manera:

... yo digo que esta parte de cuidado y atención a los otros son como actividades más relacionadas con la mujer, o sea, las actividades de servicio, y mucho más con niños pequeños o niños enfermos (P4).

Creo que, desgraciadamente, se tiene la idea ancestral, milenaria y yo me atrevo a decir atrasada que la mujer tiene 
ese "instinto materno" por naturaleza y que por eso es más apta y tiene más amor y más paciencia para trabajar con los niños en preescolar (P2).

\section{a) Actores}

El obstáculo principal para P4 fue la mesa directiva, porque los integrantes de ésta le solicitaron su traslado, notificándole que no era por su desempeño laboral, la petición se debía a que era hombre, las madres y los padres de familia no querían que estuviera al frente de un grupo, experimentan inquietud al dejar a un varón a cargo de sus hijas e hijos; en el caso de P3 afirma que se ejerció presión para que él fuera destituido de su cargo. La preocupación principal de los progenitores era el posible abuso sexual que pudiese existir, situación por la cual P4 fue obligado a permanecer dentro del aula con la puerta y las ventanas abiertas y a menudo estaba siendo supervisado por sus compañeras docentes, situación compartida por P3.

b) Prejuicio de género

Los participantes P1 y P2 comparten la idea de que el prejuicio de género, en ocasiones, es generado por ellos mismos al aceptar que el nivel preescolar es un trabajo exclusivo para las mujeres porque son tiernas y sólo tienen capacidad para ejercer ese trabajo. 


\section{c. Ventajas}

Los entrevistados mencionaron que ejercer la docencia en preescolar tiene beneficios tanto personales como sociales; dentro de los cuales se encontraron dos aspectos relevantes, a destacar: 1) El crecimiento profesional e individual y 2) Las llamadas ventajas sociales (ver figura 3).

Figura 3. Ventajas en el ejercicio docente en educación preescolar

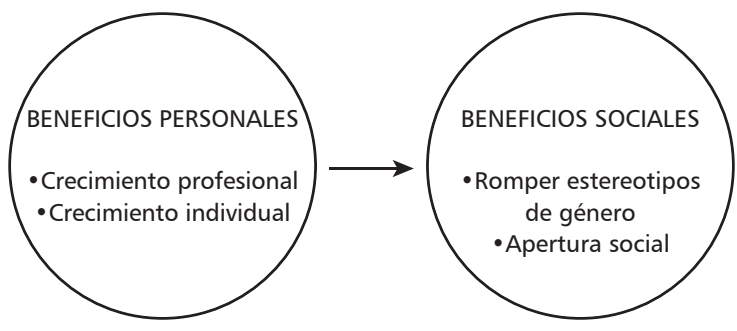

Del crecimiento profesional e individual, P1 y P2 señalaron el enriquecimiento como individuos, el desarrollo de las capacidades, sin tener que atribuir importancia especial al sexo de las personas. El docente P3 considera que es una época en la que ya se tienen que romper todas esas barreras de género.

Es necesario romper las barreras de género y mostrarle a la sociedad que los hombres también son aptos para impartir la docencia en Educación Preescolar y de contribuir a un cambio social, afirmó P1. 


\section{d. Desventajas}

La perseverancia es la clave para poder abrir espacios donde ser hombre o mujer no sea una limitante, en este caso, "fui yo el que implementó la idea de que podía haber un hombre frente al grupo" (P4).

Las desventajas expresadas se relacionan con roles de género (ver figura 4).

Figura 4. Desventajas en el ejercicio docente en preescolar

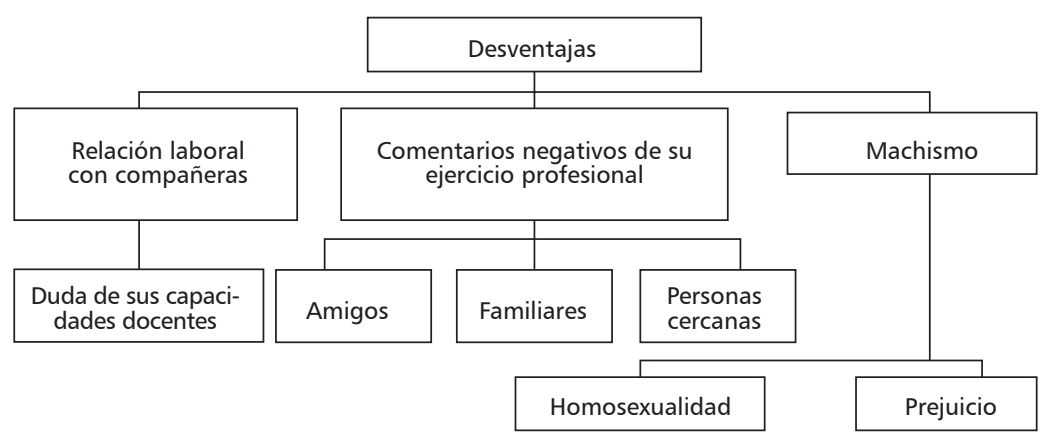

En cuanto a la relación que ellos sostienen con sus compañeras, se encontraron datos que apuntan nuevamente a estereotipos de género, expresados por las mujeres, los participantes mencionaron sentirse incompetentes pues ellas "quieren enseñarles" a trabajar. Así les sucedió a P4 y P3. Otros, como P2, experimentaron una sensación de menosprecio por la única razón de ser hombre. 
Además, constantemente es cuestionada su orientación sexual, los consideran homosexuales y pedófilos, ellos no suelen prestar atención a ese tipo de comentarios.

Por su parte, el entrevistado P4 opina que su orientación sexual también fue juzgada cuando estuvo en la docencia, sin embargo, cuando alcanzó el rango de director las dudas se disiparon.

Los prejuicios son de carácter social, pautas que dicta la sociedad y que en sí mismas o explícitamente segregan o excluyen a los hombres de determinadas profesiones, expresó P2.

Creo que todos son prejuicios construidos socialmente, creo que todos son roles, que todos son estereotipos asignados siempre por la sociedad, el mismo nombre te lo dice "Escuela Nacional de Educadoras" no dice "Escuela Nacional de formadores y formadoras de Educación Preescolar" o "Escuela Nacional para docentes de Preescolar". El nombre te lo está diciendo...

\section{e. Prospectiva}

Las expectativas profesionales que tienen los entrevistados, en tanto profesores de nivel preescolar, se centran en tomar para sí, y a manera de recomendación para otros hombres que se empleen en este ámbito educativo: la responsabilidad de resignificar para los varones el ejercicio profesional de la docencia, la sensibilidad y visión requerida para esta labor: 
Es un espacio que si está marcado por la cuestión género, pero que, sí de verdad les interesa y están dispuestos a hacer un trabajo profesional, que es algo que les gusta mucho, que les agrada, que luchen por ello y en la medida de lo posible pongan su granito de arena como yo lo estoy haciendo (P3).

Antes que nada, les diría lo que una vez me dijo mi directora de preescolar "Hagas lo que hagas, hazlo con amor." Si tú crees que a pesar de que te cuestionan, de que tú lo intentas; a pesar de que lo haces y lo haces bien, lo haces con amor, crees que el trabajar en preescolar no es el tuyo, mejor renuncia. Yo sí pienso que más vale un buen pedagogo trabajando en una dependencia del gobierno que un mal pedagogo en preescolar, porque en vez de marcar positivamente, te marcas a ti y a tus alumnos negativamente (P2).

Yo digo que la apertura sí es importante y pues simplemente también aprenderle y no darse por vencido porque sí, sí es un ambiente que a veces cuesta trabajo por los prejuicios... [También] valdría la pena ver más que ser hombre otro tipo de caracteres, el mío es muy tranquilo, no soy así como el prototipo de hombre masculino, enojón, neurótico, gritón, no. No, soy como que el otro extremo... y que a lo mejor ahí valdría la pena que no tiene que ver el ser hombre o ser 
mujer, sino con distintos caracteres y distintas formas de ejercer (P4).

\section{Reflexiones finales}

El presente estudio se centra principalmente en tres situaciones de prejuicio, discriminación y exclusión en torno a la presencia de los hombres en Educación Preescolar en la Ciudad de México: las características físicas de los varones que se perciben como un factor de riesgo para un posible abuso sexual; el constante cuestionamiento de su hombría u orientación sexual así como la capacidad para desempeñarse como docentes por el hecho de ser varones. Como lo señala King (1998), los maestros en Educación Preescolar están considerados diferentes y peligrosos. Lo anterior, permite comprender que cada suceso es histórico y que las construcciones e imaginarios sociales van transformándose con la finalidad de modificar que por razones de sexo las personas no tienen inscripciones naturales que dictan cuál es el rol que deben ejercer en la sociedad.

Es por ello que en las últimas décadas, los hombres también están teniendo acceso a otros espacios laborales, como es el de la docencia en preescolar, a pesar, del cuestionamiento de sus características, principalmente, físicas y emocionales, de la estigmatización social y la amenaza que se piensa que pueden representar para relacionarse con la infancia, ideología infundada desde la sociedad mexicana. 
En cuanto a la división sexual de las profesiones Barberá, Ramos y Candela (2006) señalan que existen trabajos más adecuados para las mujeres y otros más aptos para los hombres; razón por la cual imperan prejuicios relacionados con el sexo de las personas, al considerar que la labor docente desempeñada por los varones refiere al dudoso comportamiento de éstos, anómalas conductas que atentan y amenazan la integridad de la primer infancia. En el caso de las mujeres, regularmente se piensa que tienen atributos natos que les permiten manifestar afectividad, comprensión, paciencia y pueden ser responsables de las niñas y niños en el nivel preescolar.

Esta realidad alude a la reproducción social de normas y prescripciones que dicta la cultura acerca de cómo tienen que comportarse las mujeres y los hombres según Rocha (2005), este pensamiento limita y cuestiona la actuación profesional de las personas en este ámbito educativo.

Al respecto, los participantes de este estudio coinciden en que las actividades deberían dejar de ser pensadas para hombres o para mujeres y dar apertura a que ambos muestren su trabajo en otros espacios más allá de los habituales o cotidianos. A voz de Palencia (2009), este espacio podrá liberar tanto a hombres como a mujeres de esquemas culturales establecidos socialmente, en la medida en que se compartan las tareas y esto permita revalorar la profesión socialmente.

Este enriquecimiento mutuo será posible en tanto la crisis de la identidad masculina se transforme en lo que Cooney y Bittner (2001) llaman el "hombre reconciliado", que implica evitar la 
transmisión a las nuevas generaciones de diferencias tajantes entre lo femenino y lo masculino, al transformar la identidad que los ha posicionado como polos opuestos cuestionando el modelo de virilidad ancestral, la aceptación de una feminidad temida y la invención de otra masculinidad que promueva una forma diferente de relacionarse. Lo que se busca es que los hombres que ingresan a las licenciaturas en educación preescolar compartan con las mujeres la profesión, como en cualquier otra, y no se siga considerando una prolongación del apego materno, de esa manera los varones no necesitarán demostrar su masculinidad, sino reconciliarse con ella o, en términos de Seidler (2006) transformarla.

\section{Bibliografía}

BARberÁ, E., RAMOS, A., y CANDElA, C. (2006). "Percepción escolar de las profesiones y estereotipos de género". Psicología Educativa, pp. 133-147.

BEAUVOIR, S. (1982). El segundo sexo. La experiencia vivida. Buenos Aires: Siglo XX.

BENERÍA, L., y ROLDAN, M. (1987). The Crossroads of Class and gender. Chicago: The University of Chicago Press.

BLOUNT, J. (2005). Fit to teach: Same-sex desire, gender, and school work in the twentieth century. Nueva York: State University of New York Press.

BURIN, M., y MELER, I. (1998). Género y familia: poder, amor y sexualidad en la construcción de la subjetividad. Buenos Aires: Paidós. 
COONEY, M., y BITTNER, M. (2001). Men in early childhood education: Their emergent issues. Early Childhood Education Journal, 77-82.

CORSI, J. (1995). Violencia masculina en pareja. Buenos Aires: Paidós.

CORTADA DE KOHAN, N. (2005). El profesor y la orientación vocacional. México: Trillas.

DUBET, F. (2005). Injustices. L'expérience des inégalités au travail. París: Seuil.

FARQUHAR, S. (1997). A few good men or a few to many? A study of male teachers. Palmerstone North, Nueva Zelanda: Departament of Educational Psychology, Massey Univesrsity.

FERNÁNDEZ, B. R. (1995). Evaluación de programas. Una guía práctica en ámbitos sociales, educativos y de salud. Madrid: Síntesis.

FIFIELD, S., y SWAIN, H. (2002). "Heteronormativity and common sense in science (teacher) education”, en R. Kisson, Getting ready for Benjamin: Preparing teachers for sexual diversity in the classroom (pp. 177-190). Lanham: Rowman y Littlefield.

GARCÍA V. J. (2010). Ser hombre joven en la Ciudad de México. Tesis doctoral. México: Universidad Nacional Autónoma de México.

-, MEZA, D., y RodríGueZ, I. (2004). Estudio de masculinidad y feminidad en una muestra de jóvenes homosexuales y heterosexuales. Tesis de licenciatura. México: Universidad Nacional Autónoma de México.

HUERTA, R. (1999). El juego del hombre. Deporte y masculinidad entre obreros. México: Plaza y Valdés / BUAP.

KING, J. (1998). Uncommon caring: Learning from men who teach young children. Nueva York: Teachers College Press. 
LARA, M. A. (1993). Inventario de masculinidad y feminidad (Imafe). México: Manual Moderno.

MENDOZA, S. J. (2004). Razones y sinrazones para la elección de carreras de estudio de género con estudiantes de Educación Media Superior. México: Universidad Pedagógica Nacional.

OlVERA, R. (1997). Inventario de masculinidad y feminidad IMAFE. Tesis de licenciatura. México: Universidad Nacional Autónoma de México.

PALENCIA, V. M. (2009). "Transformaciones del modelo cultural de las educadoras de preescolar". Revista Mexicana de Investigación Educativa, 14(42), 787-811.

ROCHA, S. T., y DÍAZ, L. R. (2005). "Cultura de género: La brecha ideológica entre hombres y mujeres”. Anales de psicología, 42-49. SEIDLER, V. J. (2006). Transforming masculinities. Nueva York: Routledge.

SZASZ, I. (1998). "Sexualidad y género: algunas experiencias de investigación en México”. Debate feminista: público y privado, 77-104.

TAJIFEL, H. (1981). Human Groups and social categories. Cambridge: Cambridge University Prees.

VALLE, M. y SMITH, M. (1995). La demanda de carreras profesionales de los estudiantes de tercer año de bachillerato de ciudad Nezahualcóyotl, ciclo 1989-1990. Nezahualcóyotl, México: CISE-UNAM.

WEEMS, L. (1999). "Pestalozzi, perversity, and the pedagogy of love", en W. Letts, y J. Sears, Queering elementary education: Advancing the dialogue about sexualities and schooling (pp. 27-38). Lanham: Rowman y Littlefield. 